\title{
Potential effect of Piriformospora indica on plant growth and essential oil yield in Mentha piperita
}

\author{
Dolatabad HK ${ }^{*}$, Goltapeh EM${ }^{1}$, Safari $\mathbf{M}^{2}$ and Golafaie TP $^{3}$ \\ ${ }^{1}$ Department of Plant Protection, College of Agriculture and Natural Resources, University of Tehran, Karaj, Iran \\ ${ }^{2}$ Department of Agronomy, Tarbiat Modares University, Tehran, Iran. \\ ${ }^{3}$ Department of Government, Department of Sociology, Cornell University Alumna, Ithaca, New York, USA.
}

Dolatabad HK, Goltapeh EM, Safari M, Golafaie TP 2017 - Potential effect of Piriformospora indica on plant growth and essential oil yield in Mentha piperita. Plant Pathology \& Quarantine 7(2), 96-104, Doi 10.5943/ppq/7/2/2

\begin{abstract}
Pot culture experiments were used to evaluate the inoculation of peppermint plants (Mentha piperita) with Piriformospora indica. The effect of inoculation was observed in growth, yield, and composition of the essential oil of peppermint. Hydro distillation was used to extract oil from the dry matter of the shoot. Subsequently, GC/MS was used to determine their composition. The largest plant heights, dry shoot and root weights, and numbers of nodes were observed in pots that were inoculated with $P$. indica. The highest essential oil yield was obtained with $P$. indicainoculated plants. GC and GC/MS revealed that $P$. indica enhanced menthol levels. T-test analysis showed that differences between treatment with $P$. indica inoculation and control were significant in root length, shoot dry weight, number of nodes and essential oil yield.
\end{abstract}

Key words - Labiatae - peppermint - symbiosis

\section{Introduction}

A member of the Labiatae family, peppermint (Mentha piperita L.) is a sterile natural hybrid of M. aquatica $\times$ M. spicata (Tucker 1992). Among the ailments treated by this plant are nausea, stomach cramps, menstrual cramps, indigestion, vomiting, flatulence, and parasitosis (FonsekaKruel \& Fernandes 2003). Peppermint also possesses stimulant, carminative, antiseptic, antispasmodic, anti-inflammatory, antibacterial and antifungal properties (Guedón \& Pasquier 1994, Gershenzon et al. 2000, Inoue et al. 2002, Samarth \& Kumar 2003, Ruiz del Castillo et al. 2004, Duarte et al. 2005). Mentha piperita, as is the case for other members of the same plant group, produces various metabolites including tannins, flavonoids, terpenes, and phenolic acids (Guedón \& Pasquier 1994). Some identified compounds have been discovered as possessing antimicrobial properties including linalool, 1, 8-cineole, limonene, and menthol (Mazzanti et al. 1998, Iscan et al. 2002).

Piriformospora indica, a filamentous fungus, belongs to the order Sebacinales (Verma et al. 1998). The development of axenically cultivable $P$. indica has opened the door for the study of plant-fungi interactions. Cultivated in vitro and applied to plant hosts in controlled experiments, it is now possible to closely analyze fungi influence on plant morphogenesis and secondary 
metabolism. P. indica is able to colonize the roots of both mono- and dicotyledonous plants (Pham et al. 2004, Verma \& Arya 1998).

$P$. indica colonization can enhance crop plant yield by increasing the vegetative tissue yield, the number of inflorescences and flowers (Rai et al. 2001, Dolatabadi et al. 2011a), and the average seed weight (Rai et al. 2001, Peskan-Berghofer et al. 2004, Barazani et al. 2005). Chemical analyses revealed increased concentrations of several compounds in $P$. indica-colonized plants such as the antifungal spilanthol in Spilanthes calva (Rai et al. 2004), pharmaceutically relevant compounds such as podophyllotoxins from Linum album (Baldi et al. 2010), saponin from Chlorophytum sp. (Gosal et al. 2010) or asiaticoside from Centella asiatica (Satheesan et al. 2012) and amount of the essential oils in Thymus vulgaris and Foeniculum vulgare (Dolatabadi et al. 2011a, b, Franken 2012). In this study, we investigated the effect of $P$. indica on the performance of $M$. piperita in pot culture experiment.

\section{Materials \& Methods}

\section{Fungal culture}

Kaefer's medium was used to grow $P$. indica in petri dishes (Kaefer 1977). The fungus was used to inoculate the plates and then plates were incubated at $25 \pm 1{ }^{\circ} \mathrm{C}$ for a week.

\section{In vitro stock plant}

Stem node explants excised from the Institute of Medicinal Plants and Natural Products Research Karaj, Iran were used to create stock cultures. These explants were washed in running water. To surface sterilize, explants were immersed for 5 minutes in $70 \%$ ethanol then soaked for 10 minutes in sodium hypochlorite $(1 \%)$ with $0.01 \%$ Tween 20 . The explants were rinsed four times in sterile distilled water.

Nodes were placed in an MS medium (Murashige \& Skoog 1962). Added to this medium were $30 \mathrm{~g} / \mathrm{L}$ sucrose, $1 \mathrm{mg} / \mathrm{L}$ thiamine, and $8 \mathrm{~g} / \mathrm{L}$ agar. Prior to autoclaving for 20 minutes at 120 ${ }^{\circ} \mathrm{C}$ the $\mathrm{pH}$ was adjusted to 5.8. The explants were stored in a growth chamber under cool white fluorescent lamps that retained a constant temperature of $25{ }^{\circ} \mathrm{C}$ and a $16: 8 \mathrm{light} /$ dark photoperiod regime.

\section{In vitro plant inoculation}

For in vitro plant inoculation experiments, 30-day-old micropropagated plants provided the source of apex. A $5 \mathrm{~mm}$ diameter mycelial disc of 7-day-old culture of $P$. indica was used to inoculate the transparent culture jars destined for plant-fungus co-culture. Each culture jar contained $50 \mathrm{ml}$ of MS medium. Upon completion of the inoculation, peppermint shoots were removed from just behind the second pair of the upper leaves and then were placed into fungal discs.

\section{Pot experiment}

The plant material employed in the experiment for in vivo plant inoculation was micropropagated plants from in vitro cultures.

Following 20 days, micropropagated plants that were inoculated with $P$. indica were transferred to each pot culture and grown in a 2:1:1 sterile mixture of sand, peat, and perlite, with the following chemical properties: EC $0.9 \mathrm{ds} / \mathrm{m}, \mathrm{pH} 7.12$, total nitrogen $0.3 \%$, organic carbon $0.7 \%$, available phosphorus $8.2 \mathrm{mg} / \mathrm{kg}$ and potassium $285 \mathrm{mg} / \mathrm{kg}$ in green house at $24 / 18{ }^{\circ} \mathrm{C}$ day/night temperature. The photoperiod ranged from $16 \mathrm{~h}$ of light to $8 \mathrm{~h}$ of dark and a $7 \%$ formaldehyde solution was used to fumigate the soil.

The experiment was done with three shoots inoculated with $P$. indica and three noninoculated shoots in a completely randomized design. Plants grown in pots were analyzed after 75 days. Using the methods described by Phillip \& Hayman (1970) and Dickson et al. (1998), 
segments of the plant were stained. Using a magnification of $10-40 \times$, root pieces were analyzed with a microscope.

\section{Essential oil analysis}

Depending on the type of culture, oil was extracted from $15 \mathrm{~g}$ of the dry material through hydrodistillation in a Clevenger-like device for up to 2 hours. Anhydrous sodium sulfate was used to dry the product which was then stored in vials at $4{ }^{\circ} \mathrm{C}$ until their essential oils were analyzed. The essential oils obtained from different treatments were analyzed using gas chromatography (Thermo-UFM Model) equipped with a Ph-5 capillary column (5\% dimethylsiloxane phenyl, 10m length, $0.1 \mathrm{~mm}$ i.d. and $0.25 \mu \mathrm{m}$ film thicknesses) and FID detector. The column was programmed as follows: carrier gas, helium $0.5 \mathrm{ml} / \mathrm{min}$; injection temperature $280{ }^{\circ} \mathrm{C}$ increased to $200{ }^{\circ} \mathrm{C}$ at $5^{\circ} \mathrm{C} / \mathrm{min}$; injector temperature, $180{ }^{\circ} \mathrm{C}$; detector temperature, $220{ }^{\circ} \mathrm{C}$. The oven temperature was run from $60{ }^{\circ} \mathrm{C}$ to $285{ }^{\circ} \mathrm{C}$ at the rate of $80{ }^{\circ} \mathrm{C} / \mathrm{min}$. For the GC-MS analyses, samples were analyzed using a Varian 3400 gas chromatograph attached to a Saturn II mass spectrometer operating in electron impact ionization mode $(70 \mathrm{eV})$. The compounds were separated on DB-5HT column (30 m length, $0.25 \mathrm{~mm}$ i.d., and $0.25 \mu \mathrm{m}$ film thicknesses). The column temperature was raised from $40{ }^{\circ} \mathrm{C}$ to $250{ }^{\circ} \mathrm{C}$ at a rate of $4{ }^{\circ} \mathrm{C} / \mathrm{min}$; injector temperature, $260{ }^{\circ} \mathrm{C}$; and MS transfer line, $270{ }^{\circ} \mathrm{C}$. The components were identified by Kovats indices (KI) which compared relative to C7-C25n-alkanes and mass spectra with authentic standards as well as spectral data from library files and literature (Shibamoto 1987, Adams 1989, Davies 1990).

\section{Statistical analysis}

SAS 6.12 was used to statistically calculate the gathered data. Significant differences between treatments were determined using the $\mathrm{T}$ test.

\section{Results}

A high rate of colonization and the production of many chlamydospores in root cells were observed upon microscopic inspection of roots inoculated with $P$. indica (Fig. 1).

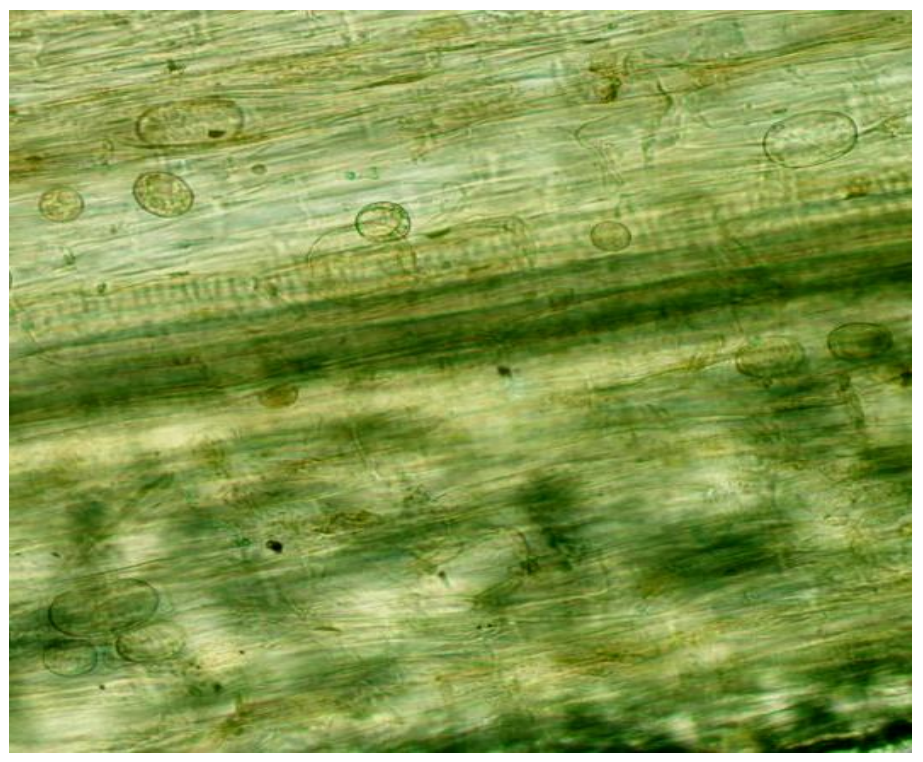

Fig. 1 - Detection of chlamydospores of Piriformospora indica in root cells of Mentha piperita.

T-test analysis showed that differences between treatment with $P$. indica inoculation and control were significant in root length, shoot dry weight, number of nodes and essential oil (Table $1, \mathrm{P}<0.05)$. 
Table 1 Effect of endophytic fungi on the growth characteristics of Mentha piperita plants grown under greenhouse condition.

\begin{tabular}{lccc}
\hline Parameter & $\begin{array}{c}\text { Piriformospora indica } \\
\text { Mean } \pm \text { SD }\end{array}$ & $\begin{array}{c}\text { Control } \\
\text { Mean } \pm \text { SD }\end{array}$ & T-test \\
\hline Plant height $(\mathrm{cm})$ & $51.47 \pm 8.62$ & $42.60 \pm 4.67$ & $\mathrm{~ns}$ \\
Root length $(\mathrm{cm})$ & $31.33 \pm 4.62$ & $19.66 \pm 4.27$ & $*$ \\
Shoot dry weight $(\mathrm{g})$ & $7.02 \pm 1.20$ & $4.2 \pm 0.99$ & $*$ \\
Root dry weight $(\mathrm{g})$ & $1.41 \pm 0.33$ & $0.90 \pm 0.17$ & $\mathrm{~ns}$ \\
Number of nodes & $252.40 \pm 17.55$ & $186.73 \pm 20.08$ & $*$ \\
Essential oil & $0.78 \pm 0.1115$ & $0.56 \pm 0.0473$ & $*$ \\
\hline
\end{tabular}

T-test: *P $\leq 0.05 ; * * \mathrm{P} \leq 0.001 ;$ ns not significant.

After 75 days, plants that were grown in cultures were analyzed. Increased vigour, extended leaves, thicker stems, and more buds and stolons were the characteristics of plants that were inoculated with $P$. indica during the experiment. $P$. indica inoculated plants were the tallest at $51.47 \mathrm{~cm}$. The control plants were at $42.6 \mathrm{~cm}$.

Similarly, $P$. indica inoculated plants possessed the longest roots $(31.33 \mathrm{~cm})$, while control plants possessed the shortest roots $(19.66 \mathrm{~cm})$ (Table 1). Likewise, measurements recorded of dry shoot weight showed differences between two treatments. Those plants that were co-cultured with $P$. indica showed the increase of the shoot dry weight as much as $67 \%$ compared to control plants. Generally, $P$. indica inoculated plants produce the highest dry root weights while control plants produced the lowest dry root weights.

Additionally, $P$. indica inoculation showed the potential of increasing the total number of nodes. The average number of nodes increased 35\% when inoculated with $P$. indica (252.4) compared to the control plants (186.73) (Table 1).

Essential oil concentration also increased in pot cultures that were inoculated with $P$. indica. Essential oil yield, both the highest $(0.78 \% \mathrm{w} / \mathrm{w})$ and the lowest $(0.56 \% \mathrm{w} / \mathrm{w})$, were observed with $P$. indica and the control (Table 1).

The gas chromatographs and essential oil compositions of $M$. piperita are shown in Fig. 2 and Table 2. The major constituents of the essential oil in $P$. indica-inoculated, and control plants were isomenthone (30.62 and $30.94 \%$, respectively), menthol (28.5 and $21.48 \%$, respectively), piperitenone (18.18 and $19.18 \%$, respectively), menthofuran (4.68 and $3.18 \%$, respectively) and pmentha-3,8-diene (2.86 and $4.53 \%$, respectively) (Table 2 ).

\section{Discussion}

Soil microorganisms can promote plant growth by transferring soil organic matter, producing plant growth regulators (PGRs), mobilizing inorganic nutrients, and acting antagonistically towards pathogens via several mechanisms (Bolton et al. 1993).

According to our results, peppermint plants are cognizant of the fitness benefits that come with association with members of the Sebacinales fungus. $P$. indica inoculation caused a complete plant reaction. Not only does $P$. indica colonize the roots of a wide variety of plant species, but also it promotes their growth and development (Sahay \& Varma 1999, Kumari et al. 2003, PeskanBerghofer et al. 2004). This study demonstrated that those plants treated with $P$. indica developed more efficiently in plant height, root length, plant and root dry weight, and essential oil yield than control plants that were not treated with $P$. indica. $P$. indica inoculation could significantly increase the root length, shoot dry weight, number of nodes and essential oil yield compared to control plants. The more intense proliferation in inoculated plants might be due to synthesized phytohormones (Singh et al. 2000, Varma et al. 2001). P. indica produces small amounts of auxins 


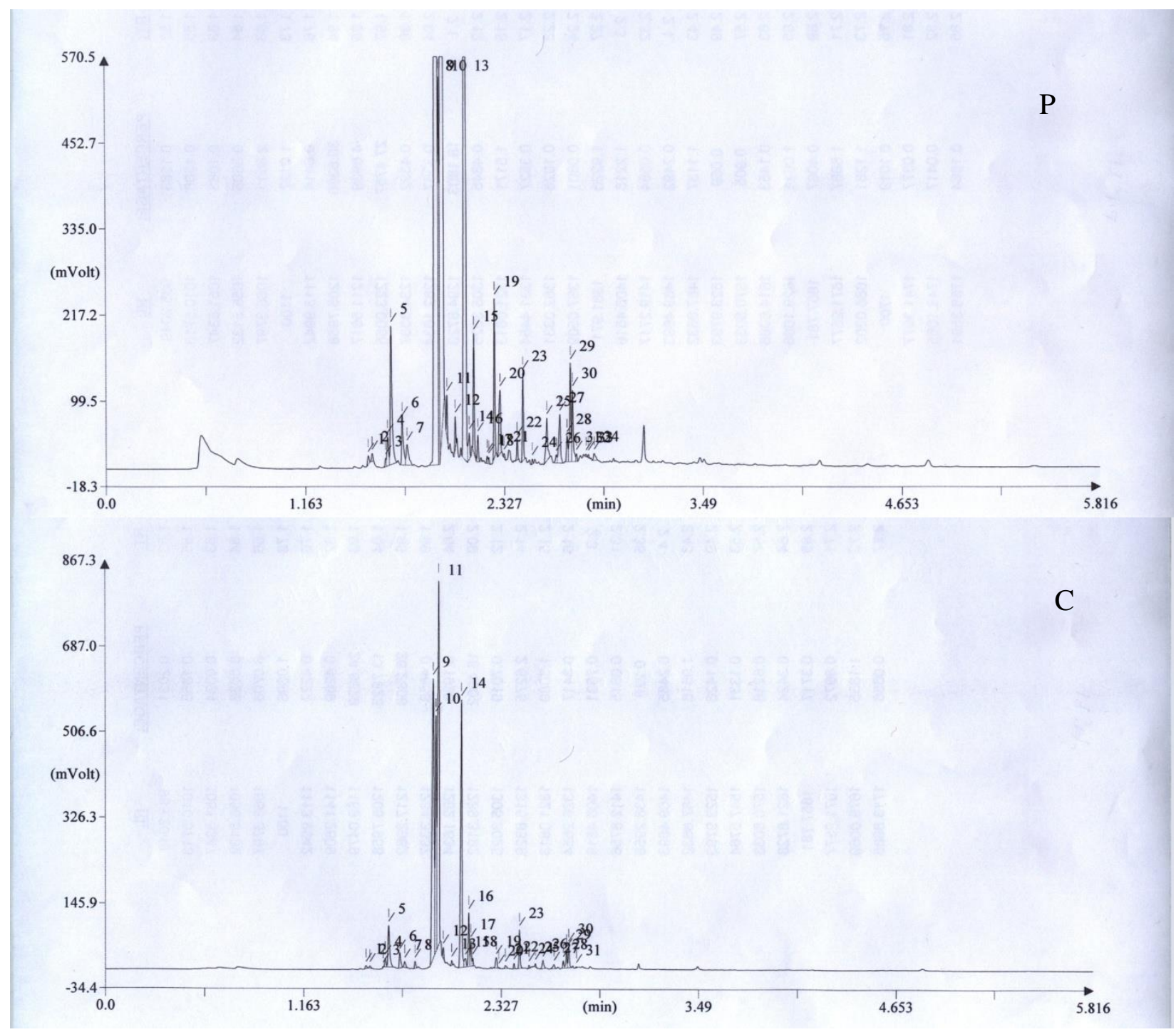

Fig. 2 - Effect of Piriformospora indica (P) in chromatogram for peppermint oil (Mentha piperita). C: control.

and relatively large amounts of cytokinins. The cytokinins levels are higher in colonized roots relative to the uncolonized roots of the control plants (Vadassery et al. 2008). Root growth and at least some of the effects of $P$. indica on the host plants are derived from the production of auxin (Sirrenberg et al. 2007). Also, differences in growth may have been caused by greater absorption of water and mineral nutrients due to extensive colonization of roots. Varma et al. (1999) reported that plants inoculated with $P$. indica showed the promotion of plant growth and biomass production. Rai et al. (2001) showed that in the presence of $P$. indica, root length, biomass, basal stem, leaf area, overall size, and the production of flowers and seeds of Spilanthes calva and Withania somenifera increased. The amount of menthol was higher in $P$. indica-inoculated plant. As noted by Mucciarelli et al. (2003), endophytic co-habitation affected the growth of peppermint while decreasing the concentration of menthofuran and increasing the concentration of menthol. In vitro and in vivo cultures of Thymus vulgaris showed that the plant height, root length, fresh and dry weight (plant and root), number of shoot nodes, oil yield, and the percentage of thymol were all improved with $P$. indica inoculation (Dolatabadi et al. 2011a). The maximum dry weight of the green tissue and root and plant height, maximum number of umbels and dry weight of 1000 fruits were obtained with $P$. indica. The $P$. indica inoculation significantly increased oil yield as compared to non-inoculated control plants. GC and GC/MS studies revealed that the level of anethole was increased with $P$. indica (Dolatabadi et al. 2011b, Oberwinkler et al. 2013). In the 
present study, our observations and data showed that $P$. indica could affect growth and increase essential oil levels of peppermint.

Table 2 Effect of Piriformospora indica inoculation on concentration (\%) of various constituents in Mentha piperita.

\begin{tabular}{|c|c|c|}
\hline \multirow[b]{2}{*}{$\begin{array}{l}\text { Essential oil } \\
\text { components }\end{array}$} & \multicolumn{2}{|c|}{ Treatments } \\
\hline & $\begin{array}{c}\text { Piriformospora } \\
\text { indica }\end{array}$ & Control \\
\hline$\gamma$ - terpinene & 0.58 & 0.46 \\
\hline$p$-mentha-3,8-diene & 2.86 & 4.53 \\
\hline Linalool & 1.04 & 3.14 \\
\hline Pulegol & 0.62 & 0.56 \\
\hline Isomenthone & 30.62 & 30.94 \\
\hline menthofuran & 4.68 & 3.18 \\
\hline menthol & 28.50 & 21.48 \\
\hline pulegone & 0.43 & 3.23 \\
\hline piperitenone & 18.18 & 19.18 \\
\hline isomenthyl acetate & 0.52 & 0.50 \\
\hline neoiso-isopulegol acetate & 1.49 & 1.38 \\
\hline piperitenone oxide & 0 & 1.18 \\
\hline geranyl acetate & 2.88 & 0 \\
\hline longifolene & 1.18 & 1.36 \\
\hline germacrene D & 1.14 & 1.02 \\
\hline$\beta$ - bisabolol & 1.56 & 1.87 \\
\hline longiborneol & 1.08 & 4.54 \\
\hline
\end{tabular}

\section{Acknowledgements}

We thank the Research Institute of Forests and Rangelands, Tehran, Iran for GC and GCmass analyses.

\section{References}

Adams RP. 1989 - Identification of essential oils by ion trap mass spectroscopy. Academic Press, New York. 302 p.

Baldi A, Farkya S, Jain A, Gupta N, Mehra R, Datta V, Srivastava AK, Bisaria VS. 2010 Enhanced production of podophyllotoxins by co-culture of transformed Linum album cells with plant growth-promoting fungi. Pure and Applied Chemistry 82, 227-241.

Barazani O, Benderoth M, Groten K, Kuhlemeier C, Baldwin IT. 2005 - Piriformospora indica and Sebacina vermifera increase growth performance at the expense of herbivore resistance in Nicotiana attenuata. Oecologia 146, 234-243. 
Bolton H, Fredrickson JK, Elliot LF. 1993 - Microbial ecology of the rhizosphere. Microbial production of plant growth regulators. In: Soil microbial ecology. Applications in agricultural and environmental management. Meeting FB Jr. (ed.) Marcel Dekker, New York, pp. 27-63.

Davies NW. 1990 - Gas chromatographic retention index of monoterpenes and sesquiterpenes on methyl silicon and carbowax 20M phases. Journal of Chromatography 503, 1-24.

Dickson S, Mandeep SM, Smith SM. 1998 - Evaluation of vesicular arbuscular mycorrhizal colonization by staining. In: Mycorrhiza manual. Varma A. (ed.), Springer-Verlag, Berlin, pp. $77-84$.

Dolatabadi HK, Goltapeh EM, Jaimand K, Rohani N, Varma A. 2011a - Effects of Piriformospora indica and Sebacina vermifera on growth and yield of essential oil in fennel (Foeniculum vulgare) under greenhouse conditions. Journal of Basic Microbiology 51, 33-39.

Dolatabadi HK, Goltapeh EM, Moieni A, Jaimand K, Sardrood BP, Varma A. 2011b - Effect of Piriformospora indica and Sebacina vermifera on plant growth and essential oil yield in Thymus vulgaris in vitro and in vivo experiments. Symbiosis 53, 29-35.

Duarte MC, Figueira GM, Sartoratto A, Rehder VL, Delarmelina C. 2005 - Anti-Candida activity of Brazilian medicinal plants. Journal of Ethnopharmacology 97, 305-311.

Fonseka-Kruel VS, Fernandes PV. 2003 - Coleção de Plantas Medicinais, Wrst ed. Instituto de Pesquisas Jardim Botânico do Rio de Janeiro, Rio de Janeiro.

Franken P. 2012 - The plant strengthening root endophyte Piriformospora indica: potential application and the biology behind. Applied Microbiology and Biotechnology 96, 14551464.

Gershenzon J, McConkey ME, Croteau RB. 2000 - Regulation of monoterpene accumulation in leaves of peppermint. Plant Physiology 122, 205-214.

Gosal SK, Karlupia A, Gosal SS, Chhibba IM, Varma A. 2010 - Biotization with Piriformospora indica and Pseudomonas fluorescens improves survival rate, nutrient acquisition, field performance and saponin content of micropropagated Chlorophytum sp. Indian Journal of Biotechnology 9, 289-297.

Guedón DJ, Pasquier BP. 1994 - Analysis and distribution of flavonoid glycosides and rosmarinic acid in 40 Mentha $x$ piperita clones. Journal of Agricultural and Food Chemistry 42, 679684.

Inoue T, Sugimoto Y, Masuda H, Kamei C. 2002 - Antiallergic effect of flavonoid glycosides obtained from Mentha piperita L. Biological and Pharmaceutical Bulletin 25, 256-259.

Iscan G, Kirimer N, Kurkcuoglu M, Baser KH, Demirci F. 2002 - Antimicrobial screening of Mentha piperita essential oils. Journal of Agricultural and Food Chemistry 50, 3943-3946.

Kaefer E. 1977 - Meiotic and mitotic recombination in Aspergillus and its chromosomal aberrations. Advances in Genetics 19, 33-131.

Kumari R, Kishan H, Bhoon YK, Varma A. 2003 - Colonization of cruciferous plants by Piriformospora indica. Current Science 85, 1672-1674.

Mazzanti G, Battinelli L, Salvatore G. 1998 - Antimicrobial properties of the linalol-rich essential oil of Hyssopus offcinalis L. var. decumbens (Lamiaceae). Flavour and Fragrance Journal 13, 289-294.

Mucciarelli M, Scannerini S, Berrtea C, Maffei M. 2003 - In vitro and in vivo peppermint (Mentha piperita) growth promotion by nonmycorrhizal fungal colonization. New Phytologist 158, 579-591.

Murashige T, Skoog F. 1962 - A revised medium for rapid growth and bioassays with tobacco tissue cultures. Physiologia Plantarum 15, 473-497.

Oberwinkler F, Riess K, Bauer R, Selosse M, Weiß M, Garnica S, Zuccaro A. 2013 - Enigmatic Sebacinales. Applied Microbiology and Biotechnology 96, 1455-1464. 
Peskan-Berghofer T, Shahollaria B, Giong PH, Hehl S, Markerta C, Blanke V, Kost G, Varma A, Oelmeuller R. 2004 - Association of Piriformospora indica with Arabidopsis thaliana roots represents a novel system to study beneficial plant-microbe interactions and involves early plant protein modifications in the endoplasmatic reticulum and at the plasma membrane. Physiologia Plantarum 122, 465-477.

Pham GH, Singh A, Kumari R, Malla R, Prasad R, Sachdev M, Rexer KH, Kost G, Luis P, Kaldorf M, Buscot F, Herrrmann S, Peskan T, Oelmüller R, Saxena AK, Declerck S, Mittag M, Stabentheinerv E, Hehl S, Varma A. 2004 - Interaction of Piriformospora indica with diverse microorganisms in plants. In: Plant surface microbiology. Varma A, Abbott L, Werner D, Hampp R. (eds), Springer-Verlag, Berlin, pp. 237-265.

Phillip JM, Hayman DS, 1970 - Improved procedures for clearing roots and staining parasitic and VAM fungi for rapid assessment of infection. Transactions of the British Mycological Society 5, 158-161.

Rai M, Acharya D, Singh A, Varma A. 2001 - Positive growth responses of the medicinal plants Spilanthes calva and Withania somnifera to inoculation by Piriformospora indica in a field trial. Mycorrhiza 11, 123-128.

Rai MK, Varma A, Pandey AK. 2004 - Antifungal potential of Spilanthes calva after inoculation of Piriformospora indica. Mycoses 47, 479-481.

Ruiz del Castillo ML, Blanch GP, Herraiz M. 2004 - Natural variability of the enantiomeric composition of bioactive chiral terpenes in Mentha piperita. Journal of Chromatography 29, 87-93.

Sahay NS, Varma A. 1999 - Piriformospora indica: a new biological hardening tool for micropropagated plants. FEMS Microbiology Letters 181, 297-302.

Samarth RM, Kumar A. 2003 - Radioprotection of Swiss albino mice by plant extract Mentha piperita (Linn.). Journal of Radiation Research 44, 101-109.

Satheesan J, Narayanan AK, Sakunthala M. 2012 - Induction of root colonization by Piriformospora indica leads to enhanced asiaticoside production in Centella asiatica. Mycorrhiza 22, 195-202.

Shibamoto T. 1987 - Retention indices in essential oil analysis. In: Capillary gas chromatography in essential oils analysis. Sandra P, Bicchi C. (eds), Dr. Alferd Huethig Verlag, New York, pp. 259-274.

Singh A, Sharma J, Rexer KH, Varma A. 2000 - Plant productivity determinants beyond minerals, water and light: Piriformospora indica-A revolutionary plant growth promoting fungus. Current Science 79(11), 1548-1554.

Sirrenberg A, Gobel C, Grond S, Czempinski N, Ratzinger A, Karlovsky P, Santos P, Feussner I, Pawlowski K. 2007 - Piriformospora indica affects plant growth by auxin production. Physiologia Plantarum 131, 581-589.

Tucker AO. 1992 - The truth about mints. Herb Companion 4, 51-52.

Vadassery J, Ritter C, Venus Y, Camehl I, Varma A, Shahollari B, Novák O, Strnad M, LudwigMüller J, Oelmüller R. 2008 - The role of auxins and cytokinins in the mutualistic interaction between Arabidopsis and Piriformospora indica. Molecular Plant-Microbe Interactions 21 (10), 1371-1383.

Varma A, Verma S, Sudha Sahay N, Bütehorn B, Franken P. 1999 - Piriformospora indica, a cultivable plant growth-promoting root endophyte. Applied and Environmental Microbiology $65,2741-2744$.

Varma A, Singh A, Sudha Sahay N, Sharma J, Roy A, Kumari M, Rana D, Thakran S, Deka D, Bharti K, Hurek T. 2001 - Piriformospora indica: an axenically culturable mycorrhiza-like endosymbiotic fungus. In: Fungal associations. Springer Berlin Heidelberg, pp. 125-150.

Verma RK, Arya ID. 1998 - Effect of arbuscular mycorrhizal fungal isolates and organic manure on growth and mycorrhization of micropropagated Dendrocalamus asper plantlets and on spore production in their rhizosphere. Mycorrhiza 8, 113-116. 
Verma S, Varma A, Rexer KH, Kost G, Sarbhoy A, Bisen P, Butehorn B, Franken P. $1998-$ Piriformospora indica, gen. et sp. nov., a new root-colonizing fungus. Mycologia 95, 896903. 